\title{
Comparative genomic analysis of ten clinical Streptococcus pneumoniae collected from a Malaysian hospital reveal 31 new unique drug-resistant SNPs using whole genome sequencing
}

\author{
Hassan Mahmood Jindal', Babu Ramanathan ${ }^{2}$, Cheng Foh Le ${ }^{3}$, Ranganath Gudimella ${ }^{4}$, Rozaimi Razali ${ }^{4}$,
} Rishya Manikam ${ }^{5}$ and Shamala Devi Sekaran ${ }^{6 *}$ (D)

\begin{abstract}
Background: Streptococcus pneumoniae or pneumococcus is a leading cause of morbidity and mortality worldwide, specifically in relation to community-acquired pneumonia. Due to the overuse of antibiotics, S. pneumoniae has developed a high degree of resistance to a wide range of antibacterial drugs.

Methods: In this study, whole genome sequencing (WGS) was performed for 10 clinical strains of S. pneumoniae with different levels of sensitivity to standard antibiotics. The main objective was to investigate genetic changes associated with antibiotic resistance in S. pneumoniae.
\end{abstract}

Results: Our results showed that resistant isolates contain a higher number of non-synonymous single nucleotide polymorphisms (SNPs) as compared to susceptible isolates. We were able to identify SNPs that alter a single amino acid in many genes involved in virulence and capsular polysaccharide synthesis. In addition, 90 SNPs were only presented in the resistant isolates, and 31 SNPs were unique and had not been previously reported, suggesting that these unique SNPs could play a key role in altering the level of resistance to different antibiotics.

Conclusion: Whole genome sequencing is a powerful tool for comparing the full genome of multiple isolates, especially those closely related, and for analysing the variations found within antibiotic resistance genes that lead to differences in antibiotic sensitivity. We were able to identify specific mutations within virulence genes related to resistant isolates. These findings could provide insights into understanding the role of single nucleotide mutants in conferring drug resistance.

Keywords: Streptococcus Pneumoniae, Antibiotic-resistance, Whole genome sequencing, Single nucleotide polymorphism, Penicillin-binding proteins

\section{Background}

Streptococcus pneumoniae is a Gram-positive human pathogen naturally inhabiting the human nasopharynx (which considered to be the reservoir as this pathogen has no animal or insect vectors) and is responsible for invasive and noninvasive diseases including meningitis, pneumonia, bacteremia, otitis media, and sinusitis [1-3].

\footnotetext{
* Correspondence: shamalamy@yahoo.com

${ }^{6}$ Department of Microbiology, Faculty of Medicine, MAHSA University, 42610 Jenjarom, Malaysia

Full list of author information is available at the end of the article
}

According to the World Health Organization (WHO), this bacterium is responsible for 1.6 million deaths annually, including $0.7-1$ million in children less than 5 years old and mostly in developing countries $[4,5]$. In the United States, the annual number of deaths caused by pneumococcal pneumonia or meningitis is $40,000[6$, 7]. In Asia, S. pneumoniae is the major cause of acute respiratory infections (ARIs) in children under 5 years old [8]. Five of the 10 countries with the largest number of deaths caused by pneumococcal infections in children below 5 years old are located in Asia, including India, 
China, Bangladesh, Pakistan, and Afghanistan [9]. Currently, more than 93 different $S$. pneumoniae serotypes have been identified based on the immunochemical differences in the capsular polysaccharides [9-11].

The mechanism used by S. pneumoniae to become pathogenic is still poorly understood, and most likely it depends on the interaction between pneumococcal virulence factors and the host's immunological response [12, 13]. For decades, penicillin has been the principle option for the treatment of infections associated with $S$. pneumoniae [14]. The main targets for penicillin and other $\beta$-lactams antibiotics are the penicillin-binding proteins (PBPs). These enzymes are essential for the synthesis of the bacterial cell wall. $\beta$-lactams act by binding to these enzymes and reducing peptidoglycan synthesis and remodeling. Subsequently, this leads to disruption of cell wall integrity and cell lysis $[15,16]$.

Like other Gram-positive bacteria, S. pneumoniae has developed significant resistance over the last few decades against a wide range of antibiotics due to extensive over-use. Mutating the target proteins such as PBPs to reduce their affinity to $\beta$-lactam antibiotics is the main resistance mechanism developed by pneumococci to resist $\beta$-lactams [17]. Moreover, S. pneumoniae has developed powerful resistance tools against erythromycin and other macrolides by modifying the target site (23S ribosomal RNA) using the erm gene or by efflux of the antibiotic from the bacterial cell through acquisition of the mef gene [18]. Tetracyclines are bacteriostatic agents that stop bacteria from reproducing by binding to the $30 \mathrm{~S}$ subunit of the bacterial ribosome. Pneumococcal resistance to tetracycline occurs through ribosomal protection mediated by $\operatorname{tet}(\mathrm{O})$ and tet $(\mathrm{M})$ genes [19]. There has been a huge increase in the number of penicillin-resistant pneumococcal isolates over the past three decades, and many strains are now resistant against common antibacterial drugs such as $\beta$ lactams, macrolides, and fluoroquinolones [20, 21]. A study conducted by Hackel and his co-workers on 2173 worldwide pneumococcal isolates, showed that $33.3 \%$ of the isolates were resistant to penicillin, $22.9 \%$ to erythromycin, and $16.2 \%$ to both erythromycin and penicillin [22].

Whole genome sequencing (WGS) has become a powerful tool for drug development by allowing researchers to investigate the mode of action of antibiotics and the mechanisms involved in bacterial resistance $[23$, 24]. Additionally, WGS can be utilised to investigate the evolution of resistance in real-time under a range of conditions [25]. In this study, we report the whole genome sequencing for 10 pneumococcal isolates with a range of susceptibility and resistance to different antimicrobial drugs to elucidate the association between antibiotic resistance and the underlying genetic changes.

\section{Methods}

\section{Bacteria and MIC determinations}

Ten pneumococcal clinical strains were collected from the microbiological specimens of patients cared for at University of Malaya Medical Centre (UMMC) over a three-year period from September 2010 to May 2012 (Table 1). All the isolated strains were stored in brain heart infusion (BHI) broth at $-80{ }^{\circ} \mathrm{C}$. Pneumococcal isolates were grown in blood agar containing $5 \%$ defibrinated sheep blood as previously described [26]. Cultures were incubated for $16-24 \mathrm{~h}$ at $37{ }^{\circ} \mathrm{C}$ under $5 \% \mathrm{CO}_{2}$. Multiplex PCR was performed to identify each strain serotype as previously described [27]. Minimal inhibitory concentration (MIC) was determined following the broth microdilution assay as described by the Clinical and Laboratory Standards Institute (CLSI) guidelines. Cation-adjusted Mueller-Hinton broth with lysed horse blood was inoculated with a $5 \times 10^{5} \mathrm{cfu} / \mathrm{mL}$ bacterial suspension. The MIC was recorded as the lowest dilution showing no visible growth. All of the results were obtained from three independent trials.

\section{Library preparation and whole genome sequencing}

A DNeasy Blood \& Tissue Kit (Qiagen) was used to extract genomic DNA from pneumococcal cells cultured overnight following the manufacturer's guidelines. Whole genome sequencing was performed using the Illumina HiSeq 2000 platform consisting of 1 lane 100 bp paired-end reads. Briefly, Covaris S2 was used to fragment all genomic DNA at the temperature of 5.5 to $6{ }^{\circ} \mathrm{C}$ for $40 \mathrm{~s}$. The fragmented DNAs were ends repaired, added with $\mathrm{dA}$ base and ligated with Illumina indexed adapters. Invitrogen $2 \%$ agarose E-gel was used for size selections of the samples. The selected DNA fragments with adapter molecules on both ends underwent ten cycles of PCR for amplification of prepared material. The

Table 1 Bacterial strains and sources used for the genomic comparison of S. pneumoniae strains

\begin{tabular}{lllll}
\hline Isolate & Isolation date & Sex & Source & Serotype $^{\text {a }}$ \\
\hline SPS1 & $15 / 9 / 2010$ & NA & Nasopharyngeal swab & NT \\
SPS2 & $21 / 5 / 2011$ & Female & Nasopharyngeal swab & 1 \\
SPS3 & $21 / 5 / 2011$ & Male & Nasopharyngeal swab & $19 F$ \\
SPS4 & $20 / 2 / 2012$ & Female & Nasopharyngeal swab & 14 \\
SPS5 & $16 / 3 / 2012$ & Female & Swab from eye & $23 F$ \\
SPS6 & $18 / 5 / 2012$ & Male & Nasopharyngeal swab & $15 B / C$ \\
SPS7 & $9 / 5 / 2011$ & Male & Blood & 1 \\
SPS8 & $8 / 3 / 2011$ & Female & Nasopharyngeal swab & 14 \\
SPS9 & $26 / 4 / 2011$ & Male & Blood & 18 \\
SPS10 & $10 / 5 / 2011$ & Male & Blood & 8 \\
\hline
\end{tabular}

all serotypes were identified using multiplex PCR as described before (Pai et al., [27])

Abbreviations: NA not available, NT non-typeable 
samples were then diluted to $10 \mathrm{nM}$ and pooled together. The libraries were loaded onto one lane of Illumina HiSeq 2000 flow cell v3 for sequencing. Illumina adapter sequences were trimmed on both ends of the reads which resulted in low quality bases on the 5 ' end of the reads. Low quality bases were removed with a quality score filter of $\geq 30$ using PRINSEQ version 0.20.3 [28].

\section{Assembly}

Assembly was performed utilising SPAdes assembler version 3.8.1 [29] by using metaSPAdes option specific for metagenome assemblies. Assembler was run using iterative kmer lengths ranging from 27 to 77 . The 10 assembled genomes were compared to the reference genome $S$. pneumoniae TIGR4 (NC_003028.3) using MetaQuast [30].

\section{Gene prediction and clustering}

Genes prediction on the draft assemblies was performed by using the Prokka (Prokaryotic annotation) tool. Functionally, Prokka predicts genes based on available annotation information such as CDS and proteins. It builds HMM databases which are searched by using HMMER3. Prokka was run using customised parameters that were set to annotate against reference genome $S$. pneumoniae TIGR4 with an evalue of 1e-10. To create gene clusters among 10 isolates and the reference genome all the amino acid sequences in fasta format were retrieved. All proteins were subjected for BLASTp (e.value $<1 \mathrm{e}-5$ ) against the same set of sequences in order to perform all versus all blast. A connection (edge) between two genes was assigned if more than one third of the region aligned to both genes. An h-score (0 to 100) was used to weight the similarity (edge). For two genes G1 and G2, the Hscore was defined as score (G1G2) / max (score (G1G1), score (G2G2); the score used here was the BLAST raw score. Gene families were identified by using clustering by Hcluster_sg [31]. We used the average distance for the hierarchical clustering algorithm, with the parameters of minimum edge weight set to 5 and the minimum edge density (total number of edges / theoretical number of edges) set to 0.35 .

\section{Variant calling and phylogeny}

Single nucleotide polymorphisms (SNPs) were identified using kSNP3 program (version 3.021) which identifies pan-genome SNPs in a set of genome sequences and builds a phylogenetic tree based on the SNPs [32]. kSNP3 was run using the standard mode of SNP detection and annotation using S. pneumoniae TIGR4 as reference with Kmer size of 11 . Kmer was calculated by Kchooser program which accurately defines a kmer size based on the draft genome assemblies. Phylogeny trees are parsimony trees based on consensus trees from different samples. Although parsimony trees do not define evolution lineage, they do help to define the nearer samples based on changes per number of SNPs. A complex heat map package from Bioconductor was used to generate heat maps in R. Clusters are predicted using Euclidean distance method.

\section{Statistical analysis}

Statistical analysis testing the difference in SNP number between the antibiotic resistant and susceptible isolates was performed using two-sample Student's t-test with a significant level at $p<0.05$.

\section{Results}

Selection and whole-genome sequencing of $S$. pneumoniae

Ten isolates were selected from a larger collection of pneumococcal isolates according to their susceptibility to four different antibiotics: penicillin, cefotaxime, erythromycin, and tetracycline. Table 2 summarises the MICs for all 10 isolates. Isolates SPS1, SPS2, and SPS3 were non-susceptible to all antibiotics; isolate SPS4 was susceptible to penicillin, cefotaxime, and erythromycin; SPS5 exhibited susceptibility to cefotaxime and erythromycin, but it showed resistance to penicillin and tetracycline. Isolate SPS6 was susceptible to all four antibiotics; conversely, isolates SPS7 and SPS10 were resistant to all four antibiotics. Isolates SPS8 and SPS9 were resistant to all antibiotics but they showed susceptibility to penicillin.

The WGSs of all 10 isolates were conducted to investigate the association between antibiotic-resistance and

Table 2 Antibiotic susceptibility profiles of S. pneumoniae isolates

\begin{tabular}{|c|c|c|c|c|}
\hline \multirow{2}{*}{$\begin{array}{l}\text { Isolate } \\
\text { a }\end{array}$} & \multicolumn{4}{|c|}{$\mathrm{MIC}(\mu \mathrm{g} / \mathrm{ml})^{\mathrm{b}}$} \\
\hline & $\mathrm{PEN}^{\mathrm{c}}$ & CTX ${ }^{c}$ & ERY ${ }^{c}$ & TET $^{c}$ \\
\hline SPS1 & 2 & 1 & 2 & 16 \\
\hline SPS2 & 2 & 1 & $>2$ & $>16$ \\
\hline SPS3 & 4 & 1 & $>2$ & $>16$ \\
\hline SPS4 & 0.06 & $\leq 0.063$ & $\leq 0.016$ & $>16$ \\
\hline SPS5 & 1 & 0.125 & 0.031 & 4 \\
\hline SPS6 & 0.06 & $\leq 0.063$ & $\leq 0.016$ & $\leq 0.125$ \\
\hline SPS7 & 2 & 2 & $>2$ & $>16$ \\
\hline SPS8 & 0.5 & $>8$ & 2 & $>16$ \\
\hline SPS9 & 0.25 & 8 & 2 & 16 \\
\hline SPS10 & 2 & 2 & $>2$ & 16 \\
\hline
\end{tabular}

asolates SPS1, SPS2, and SPS3 are non-susceptible to all antibiotics. Isolate SPS4 is susceptible to penicillin, cefotaxime, and erythromycin, but resistant to tetracycline. SPS5 is susceptible to cefotaxime and erythromycin, but resistant to penicillin and tetracycline. SPS6 is susceptible to all four antibiotics. SPS7 and SPS10 are resistant to all four antibiotics, SPS8 and SPS9 were resistant to all antibiotics except penicillin

${ }^{\mathrm{b}}$ MIC Minimum inhibitory concentration

CPEN Penicillin, CTX Cefotaxime, ERY Erythromycin, TET Tetracycline 
the underlying genomics variations. The genomic DNA of all the isolates was sequenced using the Illumina HiSeq 2000 platform. The draft genome assemblies for the 10 isolates have been submitted to the NCBI BioProject under the project accession number PRJNA317517 (http://www.ncbi.nlm.nih.gov/bioproject/317517). The sequencing consisted of one lane $100 \mathrm{bp}$ paired-end reads, yielding approximately $0.6 \mathrm{Gbp}$ to $3.6 \mathrm{Gbp}$ for $S$. pneumoniae. More than $80 \%$ of the reads were above a Phred quality score of 30 indicating the high-quality of the sequencing data. The overall GC\% content for all 10 isolates ranged from 39.12 to $39.72 \%$ and was similar to that of the TIGR4 reference genome (39.7\%) [33]. The number of genes was 2352 and 2159 for SPS1 and SPS2, respectively. SPS3, SPS4, SPS5, and SPS6 had gene contents of 1983, 1983, 2020, and 1984, respectively. SPS7, SPS8, SPS9, and SPS10 showed gene contents of 2064, 1980, 2035, and 1924, respectively (Additional file 1). The number of tRNAs was also similar for all the 10 isolates in the range of 41-46 (Additional file 1). Figure 1 represents a circular map of the ten pneumococcal clinical isolates compared to the reference genome of isolate TIGR4. All 10 isolates showed $>90 \%$ identity with the reference genome. Different colours represent the BLASTn matches between $70 \%$ to $100 \%$ nucleotide identities. The full assembly and gene content for each pneumococcal isolate can be found in Additional file 1.

\section{Core genome polymorphism}

To identify sequence variations, WGS reads from each strain were mapped to the TIGR4 reference genome of S. pneumoniae using the Bowtie2 software [34]. The genome sequences of all the clinical isolates revealed a high level of similarity and the virulence genes that are known to be involved in drug-resistance are well conserved among all the 10 isolates (Table 3). In order to identify differences that alter the level of resistance of these clinical isolates we focused on identifying SNPs in genes engaged with antibiotics pathways. Table 4 represents the total number of SNPs identified for each isolate, which ranged from 3600 to 6548 SNPs. SNPs that cause a change in amino acids, start codons, and stop codons were classified as "non-synonymous SNPs". Figure 2 illustrates the distribution of all SNPs in both antibiotic resistant and susceptible isolates. The majority of these non-synonymous SNPs associated with pneumococcal essential genes were present in antibiotic resistant strains $(p=0.016)$. Penicillin-resistant isolates showed 3301 SNPs, while susceptible isolates had only 281 SNPs. 6343 SNPs were associated with tetracyclineresistant isolates compared to only 21 SNPs associated with isolate SPS6 (Fig. 2). Similarly, ceftriaxone and erythromycin resistant isolates showed greater number of SNPs (5234) compared to 111 SNPs in susceptible isolates (Fig. 2). The complete list of SNPs in the 10

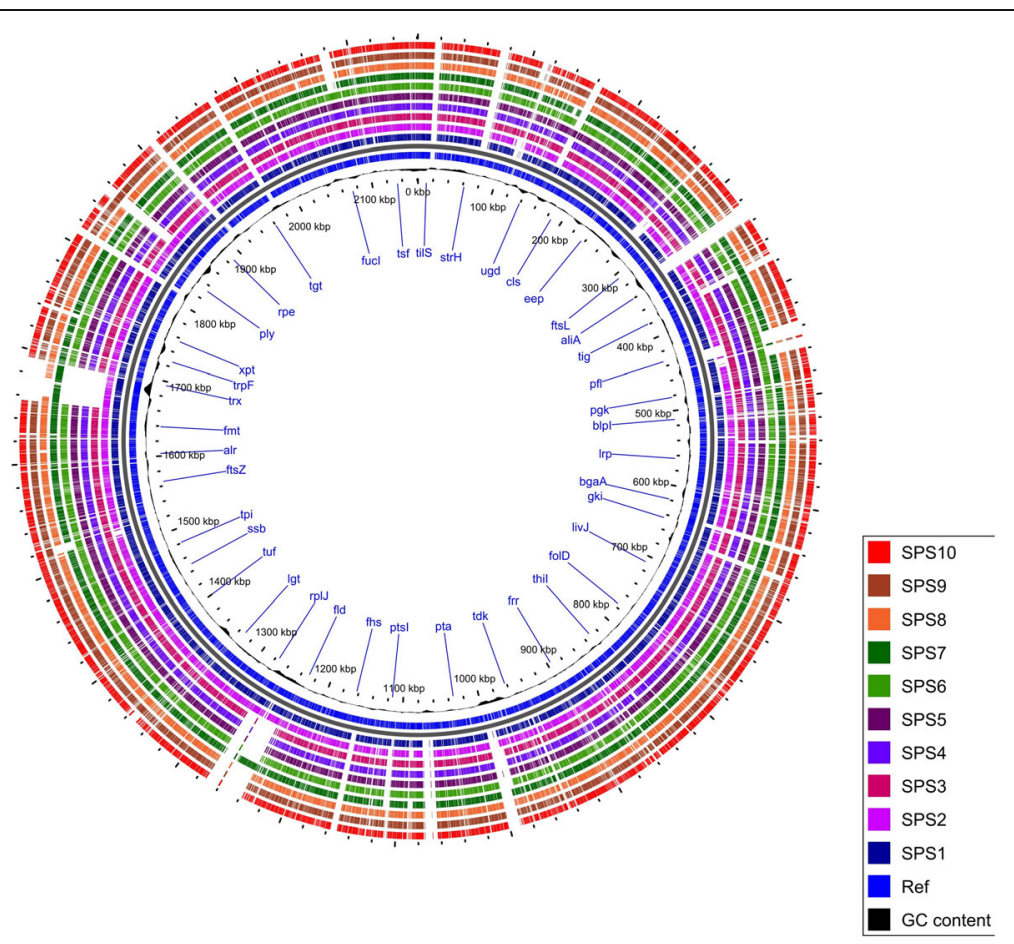

Fig. 1 Circular genome map of 10 S. pneumoniae isolates compared to reference genome TIGR4. Rings from the outside inward: SP10, SP09, SP08, SP07, SP06, SP05, SP04, SP03, SP02, SP01, and reference genome S. pneumoniae TIGR4 (NC_003028.3). The blank spaces in the rings represent matches with lesS than $70 \%$ or no BLAST matches to the reference genome. The image was prepared using Blast Ring Image Generator [51] 
Table 3 Presence and absence of genes involved in virulence and antibiotic-resistance in each of the 10 clinical isolates

\begin{tabular}{|c|c|c|c|c|c|c|c|c|c|c|c|}
\hline \multirow{2}{*}{$\begin{array}{l}\text { Locus } \\
\text { name }^{a}\end{array}$} & \multirow[t]{2}{*}{ Gene name and/or description } & \multicolumn{10}{|c|}{ Presence of virulent genes in Pneumococcal isolates } \\
\hline & & SPS01 & SPSO2 & SPSO3 & SPSO4 & SPS05 & SPS06 & SPS07 & SPS08 & SPS09 & SPS10 \\
\hline SP_0531 & blpl; bacteriocin & 1 & 1 & 0 & 0 & 0 & 0 & 0 & 0 & 1 & 0 \\
\hline SP_0041 & blpU; bacteriocin & 1 & 1 & 1 & 1 & 1 & 1 & 1 & 1 & 0 & 1 \\
\hline SP_0109 & bacteriocin & 1 & 1 & 0 & 0 & 0 & 0 & 1 & 1 & 1 & 1 \\
\hline SP_0544 & immunity protein BIpX & 1 & 1 & 0 & 0 & 0 & 0 & 1 & 1 & 0 & 1 \\
\hline SP_1315 & V-type ATP synthase subunit D & 1 & 1 & 0 & 0 & 0 & 0 & 1 & 0 & 0 & 0 \\
\hline SP_1318 & V-type ATP synthase subunit F & 1 & 1 & 0 & 0 & 0 & 0 & 1 & 0 & 0 & 0 \\
\hline SP_1319 & V-type ATP synthase subunit $C$ & 1 & 1 & 0 & 0 & 0 & 0 & 1 & 0 & 0 & 0 \\
\hline SP_1320 & V-type ATP synthase subunit E & 1 & 1 & 0 & 0 & 0 & 0 & 1 & 0 & 0 & 0 \\
\hline SP_1321 & V-type ATP synthase subunit $K$ & 1 & 1 & 0 & 0 & 0 & 0 & 1 & 0 & 0 & 0 \\
\hline SP_1322 & V-type ATP synthase subunit I & 1 & 1 & 0 & 0 & 0 & 0 & 1 & 0 & 0 & 0 \\
\hline SP_0346 & $\begin{array}{l}\text { cpsA; capsular polysaccharide } \\
\text { biosynthesis protein }\end{array}$ & 1 & 1 & 1 & 1 & 1 & 1 & 1 & 1 & 1 & 1 \\
\hline SP_0347 & $\begin{array}{l}\text { cpsB; capsular polysaccharide } \\
\text { biosynthesis protei }\end{array}$ & 1 & 1 & 1 & 1 & 1 & 1 & 1 & 1 & 1 & 1 \\
\hline SP_0348 & $\begin{array}{l}\text { cpsC; capsular polysaccharide } \\
\text { biosynthesis protein }\end{array}$ & 1 & 1 & 1 & 1 & 1 & 1 & 1 & 1 & 1 & 1 \\
\hline SP_0349 & $\begin{array}{l}\mathrm{Cps} D \text {; capsular polysaccharide } \\
\text { biosynthesis protein }\end{array}$ & 1 & 1 & 1 & 1 & 1 & 1 & 1 & 1 & 1 & 1 \\
\hline SP_0350 & $\begin{array}{l}\text { cpsE; capsular polysaccharide } \\
\text { biosynthesis protein }\end{array}$ & 1 & 1 & 1 & 1 & 1 & 1 & 1 & 1 & 1 & 1 \\
\hline SP_0117 & $\begin{array}{l}\text { pspA; pneumococcal surface } \\
\text { protein A }\end{array}$ & 1 & 1 & 1 & 1 & 1 & 1 & 1 & 1 & 1 & 1 \\
\hline SP_0377 & cbpC; choline-binding protein C & 1 & 1 & 1 & 1 & 1 & 1 & 1 & 1 & 1 & 1 \\
\hline SP_0378 & cbpJ; choline-binding protein J & 1 & 1 & 1 & 1 & 1 & 1 & 1 & 1 & 1 & 1 \\
\hline SP_0390 & cbpG; choline-binding protein $\mathrm{G}$ & 1 & 1 & 1 & 1 & 1 & 1 & 1 & 1 & 1 & 1 \\
\hline SP_0391 & cbpF; choline-binding protein F & 1 & 1 & 1 & 1 & 1 & 1 & 1 & 1 & 1 & 1 \\
\hline SP_0533 & blpK; bacteriocin associated protein & 1 & 1 & 1 & 1 & 1 & 1 & 1 & 1 & 1 & 1 \\
\hline SP_0545 & blpY; Immunity protein & 1 & 1 & 1 & 1 & 1 & 1 & 1 & 1 & 1 & 1 \\
\hline SP_0641 & prtA; protective antigen $A$ & 1 & 1 & 1 & 1 & 1 & 1 & 1 & 1 & 1 & 1 \\
\hline SP_1638 & PsaR; transcriptional regulator & 1 & 1 & 1 & 1 & 1 & 1 & 1 & 1 & 1 & 1 \\
\hline SP_0966 & $\begin{array}{l}\text { pavA; adherence and virulence } \\
\text { protein A }\end{array}$ & 1 & 1 & 1 & 1 & 1 & 1 & 1 & 1 & 1 & 1 \\
\hline SP_1923 & pln; pneumolysin & 1 & 1 & 1 & 1 & 1 & 1 & 1 & 1 & 1 & 1 \\
\hline SP_1937 & lytA; autolysin & 1 & 1 & 1 & 1 & 1 & 1 & 1 & 1 & 1 & 1 \\
\hline SP_2190 & chpA; choline-binding protein A & 1 & 1 & 1 & 1 & 1 & 1 & 1 & 1 & 1 & 1 \\
\hline SP_2201 & chpD; choline-binding protein D & 1 & 1 & 1 & 1 & 1 & 1 & 1 & 1 & 1 & 1 \\
\hline SP_0457 & bacA; bacitracin resistance protein & 1 & 1 & 1 & 1 & 1 & 1 & 1 & 1 & 1 & 1 \\
\hline SP_0615 & fibA; beta-lactam resistance factor & 1 & 1 & 1 & 1 & 1 & 1 & 1 & 1 & 1 & 1 \\
\hline SP_1673 & penA; penicillin-binding protein $2 B$ & 1 & 1 & 1 & 1 & 1 & 1 & 1 & 1 & 1 & 1 \\
\hline SP_0369 & penicillin-binding protein $1 \mathrm{~A}$ & 1 & 1 & 1 & 1 & 1 & 1 & 1 & 1 & 1 & 1 \\
\hline SP_2099 & penicillin-binding protein $1 \mathrm{~B}$ & 1 & 1 & 1 & 1 & 1 & 1 & 1 & 1 & 1 & 1 \\
\hline SP_2010 & penicillin-binding protein $2 \mathrm{~A}$ & 1 & 1 & 1 & 1 & 1 & 1 & 1 & 1 & 1 & 1 \\
\hline SP_0336 & penicillin-binding protein $2 X$ & 1 & 1 & 1 & 1 & 1 & 1 & 1 & 1 & 1 & 1 \\
\hline SP_0616 & beta-lactam resistance factor & 1 & 1 & 1 & 1 & 1 & 1 & 1 & 1 & 1 & 1 \\
\hline SP_0798 & ciaR; DNA-binding response regulator & 1 & 1 & 1 & 1 & 1 & 1 & 1 & 1 & 1 & 1 \\
\hline SP_0799 & ciaH; sensor histidine kinase & 1 & 1 & 1 & 1 & 1 & 1 & 1 & 1 & 1 & 1 \\
\hline SP_0972 & pmrA; multi-drug resistance efflux pump & 1 & 1 & 1 & 1 & 1 & 1 & 1 & 1 & 1 & 1 \\
\hline SP_0461 & transcriptional regulator & 0 & 0 & 1 & 1 & 1 & 1 & 0 & 0 & 0 & 0 \\
\hline
\end{tabular}

All S. pneumoniae loci number (sp_\#) are according to the annotation of reference strain TIGR4. 1 indicates presence and 0 indicates absence of the gene from the pneumococcal isolates 
Table 4 The total number of non-synonymous SNPs for each pneumococcal isolate

\begin{tabular}{lll}
\hline Isolate & No. of SNPs & SNPs in protein coding \\
\hline SPS1 & 3600 & 3180 \\
SPS2 & 2847 & 2522 \\
SPS3 & 6297 & 5611 \\
SPS4 & 6339 & 5668 \\
SPS5 & 6359 & 5675 \\
SPS6 & 6411 & 5731 \\
SPS7 & 6704 & 5998 \\
SPS8 & 6440 & 5761 \\
SPS9 & 6452 & 5776 \\
SPS10 & 6548 & 5875 \\
\hline
\end{tabular}

isolates sequenced and the TIGR4 reference genome can be found in Additional file 2. To explore the potential link between sequence variants with virulence characteristics, non-synonymous polymorphisms were extracted from genes annotated as virulence factors or involved in bacterial resistance $[35,36]$ (Table 4). The conserved nonsynonymous polymorphisms in all resistant pneumococcal isolates were identified. These SNPs could possibly play an important biological role as they result in stop codons or frame shifts in protein sequence (Table 5). A total of 16 genes with 90 non-synonymous SNPs found only in the resistant isolates were identified. The presence of some of these SNPs in more than one resistant isolate suggests that these SNPs or a subset of them might have potential roles in antibiotic resistance. For example, the same mutation (G597E) associated with penicillin binding protein PBP2b was found in four different resistant isolates SPS7, SPS8, SPS9, and SPS10. Similarly, mutation (T23A) associated with virulent gene pneumococcal surface protein A (PspA) was identified in four resistant isolates SPS1, SPS7, SPS8, and SPS9 (Additional file 3). By blasting our sequences, we were able to identify 31 unique nonsynonymous SNPs associated with penicillin binding proteins (PBPs) and other virulent genes that were not previously published (Table 6).

The numbers of non-synonymous SNPs corresponding to the selected genes essential for bacterial survival and virulence based on previous literatures [37-39] in each isolate are presented in Table 5. Figure 3 represents the number of non-synonymous SNPs that are in genes

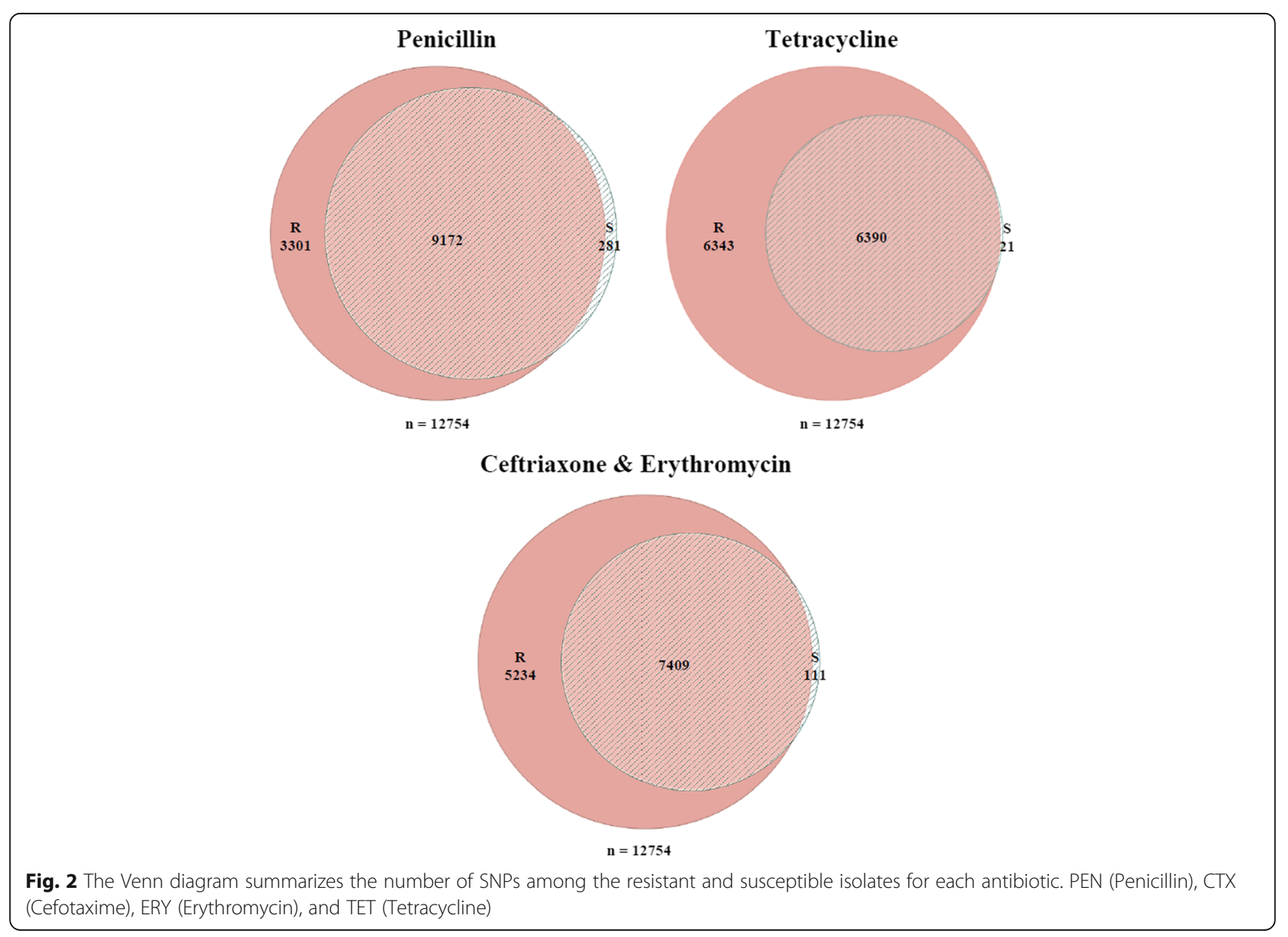


Table 5 Non-synonymous SNPs among S. pneumoniae isolates found in genes associated with virulence, antibiotic resistance, and other regulatory functions

\begin{tabular}{|c|c|c|c|c|c|c|c|c|c|c|c|}
\hline \multirow{2}{*}{$\begin{array}{l}\text { Locus } \\
\text { name }^{a}\end{array}$} & \multirow[t]{2}{*}{ Gene name and/or description } & \multicolumn{10}{|c|}{ No. of SNPs in Pneumococcal isolates } \\
\hline & & SPS01 & SPSO2 & SPSO3 & SPSO4 & SPS05 & SPS06 & SPS07 & SPS08 & SPS09 & SPS10 \\
\hline SP_0041 & blpU; bacteriocin & 1 & 1 & 1 & 1 & 1 & 1 & 1 & 1 & - & 2 \\
\hline SP_0346 & cpsA; capsular polysaccharide biosynthesis protein & 7 & 5 & 4 & 4 & 4 & 4 & 8 & 8 & 8 & 8 \\
\hline SP_0347 & cpsB; capsular polysaccharide biosynthesis protein & 1 & 2 & - & - & - & - & 1 & 1 & 1 & 5 \\
\hline SP_0348 & cpsC; capsular polysaccharide biosynthesis protein & 1 & 3 & 3 & 3 & 3 & 3 & 2 & 2 & 2 & 6 \\
\hline SP_0349 & cpsD; capsular polysaccharide biosynthesis protein & 7 & - & 11 & 11 & 12 & 12 & 5 & 5 & 9 & - \\
\hline SP_0350 & cpsE; capsular polysaccharide biosynthesis protein & - & - & - & - & - & - & - & - & - & - \\
\hline SP_0351 & cpsF; capsular polysaccharide biosynthesis protein & - & - & - & - & - & - & - & - & - & - \\
\hline SP_0352 & cpsG; capsular polysaccharide biosynthesis protein & - & - & - & - & - & - & - & - & - & - \\
\hline SP_0353 & cpsH; capsular polysaccharide biosynthesis protein & - & - & - & - & - & - & - & - & - & - \\
\hline SP_1837 & capsular polysaccharide biosynthesis protein & 4 & 3 & - & - & - & - & 3 & 3 & 4 & 4 \\
\hline SP_0117 & pspA; pneumococcal surface protein A & 2 & - & 4 & 2 & 3 & 4 & 5 & 5 & 4 & 3 \\
\hline SP_0377 & cbpC; choline-binding protein C & 6 & 3 & 5 & 5 & 5 & 5 & 1 & 1 & - & 1 \\
\hline SP_0930 & cbpE; choline-binding protein E & 7 & 8 & 12 & 11 & 13 & 12 & 3 & 3 & 11 & 5 \\
\hline SP_0378 & cbpJ; choline-binding protein J & 1 & 3 & 2 & 2 & 2 & 2 & 1 & 1 & - & 1 \\
\hline SP_0390 & cbpG; choline-binding protein $G$ & 3 & 6 & 4 & 4 & 2 & 4 & 4 & 4 & 3 & 1 \\
\hline SP_0391 & cbpF; choline-binding protein F & 5 & 6 & - & - & - & - & - & - & - & - \\
\hline SP_0069 & cbpl; choline-binding protein I & - & - & - & - & - & - & - & - & - & - \\
\hline SP_0533 & blpk; bacteriocin associated protein & - & - & - & - & - & - & - & - & - & - \\
\hline SP_0545 & blpY; Immunity protein & 2 & 3 & 3 & 3 & 2 & 2 & 2 & 2 & - & 1 \\
\hline SP_0641 & prtA; protective antigen $A$ & 16 & 14 & 13 & 12 & 12 & 13 & 14 & 14 & 9 & 13 \\
\hline SP_0730 & spxB; pyruvate oxidase & 1 & 1 & - & - & - & - & - & - & 1 & - \\
\hline SP_1002 & Imb; adhesion lipoprotein & - & - & - & - & - & - & - & - & - & 3 \\
\hline SP_1003 & Conserved hypothetical protein & 7 & 6 & 5 & 3 & 4 & 5 & 8 & 8 & 4 & 4 \\
\hline SP_1207 & xseA; exodeoxyribonuclease VII, large subunit & - & - & - & - & - & - & - & - & - & - \\
\hline SP_1923 & pln; pneumolysin & 1 & 1 & - & - & - & - & 2 & 2 & 2 & 3 \\
\hline SP_1937 & lytA; autolysin & 1 & 4 & 1 & 1 & 1 & 1 & 1 & 1 & 1 & - \\
\hline SP_2190 & chpA; choline-binding protein A & 6 & 11 & 9 & 10 & 7 & 8 & 2 & 2 & 4 & 9 \\
\hline SP_2201 & chpD; choline-binding protein D & 3 & 4 & 4 & 4 & 4 & 4 & 6 & 6 & 3 & 8 \\
\hline SP_2239 & htrA; serine protease & - & 1 & - & - & - & - & 1 & 1 & 2 & 2 \\
\hline SP_2240 & spoj; homologous to sporulation protein & 1 & - & 2 & 2 & 2 & 2 & 1 & 1 & 1 & 1 \\
\hline SP_0457 & bacA; bacitracin resistance protein & - & - & - & - & - & - & - & - & - & - \\
\hline SP_0615 & fibA; beta-lactam resistance factor & - & 1 & 1 & 2 & 2 & 1 & 2 & 1 & 1 & 4 \\
\hline SP_1673 & penA; penicillin-binding protein $2 \mathrm{~B}$ & 1 & 6 & 3 & 1 & 5 & 5 & 2 & 2 & 3 & 2 \\
\hline SP_0369 & penicillin-binding protein $1 \mathrm{~A}$ & 3 & 2 & 1 & 2 & 1 & 1 & 2 & 2 & - & 3 \\
\hline SP_2099 & penicillin-binding protein 1B & 3 & 2 & 4 & 4 & 4 & 4 & 3 & 3 & 4 & 4 \\
\hline SP_2010 & penicillin-binding protein 2A & 4 & 5 & 5 & 5 & 5 & 5 & 1 & 1 & 7 & 5 \\
\hline SP_0336 & penicillin-binding protein $2 X$ & 1 & 1 & 3 & 2 & 1 & 2 & 2 & 2 & 4 & 3 \\
\hline SP_0616 & beta-lactam resistance factor & 2 & 1 & 1 & 2 & 2 & 1 & 4 & 4 & 3 & 2 \\
\hline SP_1075 & CpoA; glycosyl transferase & 1 & 1 & 1 & 1 & 1 & 1 & - & - & 1 & 1 \\
\hline SP_0798 & ciaR; DNA-binding response regulator & - & 1 & - & 1 & - & - & - & - & - & - \\
\hline SP_0799 & $\mathrm{ciaH}$; sensor histidine kinase & - & - & - & - & - & - & 1 & 1 & - & - \\
\hline SP_2084 & pstS; phosphate $A B C$ transporter, phosphate-bind & - & - & - & - & - & - & - & - & - & 1 \\
\hline
\end{tabular}


Table 5 Non-synonymous SNPs among S. pneumoniae isolates found in genes associated with virulence, antibiotic resistance, and other regulatory functions (Continued)

\begin{tabular}{|c|c|c|c|c|c|c|c|c|c|c|c|}
\hline \multirow{2}{*}{$\begin{array}{l}\text { Locus } \\
\text { name }^{\text {a }}\end{array}$} & \multirow[t]{2}{*}{ Gene name and/or description } & \multicolumn{10}{|c|}{ No. of SNPs in Pneumococcal isolates } \\
\hline & & SPS01 & SPSO2 & SPSO3 & SPSO4 & SPS05 & SPS06 & SPS07 & SPS08 & SPSO9 & SPS10 \\
\hline SP_2085 & pstC; phosphate $A B C$ transporter, permease protein & - & 2 & 3 & 3 & 3 & 3 & 2 & 2 & 1 & 1 \\
\hline SP_2086 & pstA; phosphate $A B C$ transporter, permease protein & - & - & - & - & - & - & - & - & - & - \\
\hline SP_2087 & pstB; phosphate ABC transporter, ATP-binding protein & 3 & 3 & 1 & 1 & 1 & 1 & - & - & 1 & - \\
\hline SP_1890 & amiC; oligopeptide $A B C$ transporter permease & 2 & 3 & 3 & 3 & 3 & 3 & 4 & 4 & 4 & 2 \\
\hline SP_0010 & beta-lactamase class $C$ & 4 & - & 1 & 1 & 1 & 1 & - & - & 1 & 1 \\
\hline SP_0314 & hyaluronate lyase & 14 & 14 & 15 & 15 & 15 & 15 & 16 & 16 & 10 & 14 \\
\hline SP_0071 & metalloprotease ZmpC & - & - & - & - & - & - & - & - & - & - \\
\hline SP_1650 & manganese $A B C$ transporter substrate-binding lipoprotein & 1 & 1 & 1 & 1 & 1 & 1 & 1 & 1 & 1 & 1 \\
\hline SP_1687 & neuraminidase B & 7 & 7 & 8 & 4 & 4 & 8 & 5 & 5 & 5 & 4 \\
\hline SP_0357 & UDP-N-acetyl glucosamine 2-epimerase Cpsl & - & - & - & - & - & - & - & - & - & - \\
\hline SP_0358 & capsular polysaccharide biosynthesis protein CpsJ & - & - & - & - & - & - & - & - & - & - \\
\hline SP_0359 & capsular polysaccharide biosynthesis protein CpsK & - & - & - & - & - & - & - & - & - & - \\
\hline SP_0360 & UDP-N-acetyl glucosamine 2-epimerase CpsL & - & - & - & - & - & - & - & - & - & - \\
\hline SP_0463 & cell wall surface anchor protein & - & - & 1 & 1 & 1 & 1 & - & - & - & - \\
\hline SP_0461 & transcriptional regulator & - & - & - & - & 1 & - & - & - & - & - \\
\hline SP_0468 & sortase & - & - & - & - & - & - & - & - & - & - \\
\hline SP_0965 & endo-beta-N-acetylglucosaminidase LytB & 2 & 2 & 2 & 2 & 2 & 2 & 1 & 1 & 1 & 2 \\
\hline SP_1783 & DNA mismatch repair protein MutT & - & - & 1 & 1 & 1 & 1 & - & - & - & 1 \\
\hline SP_0173 & DNA mismatch repair protein $\mathrm{HexB}$ & - & - & - & - & - & - & - & - & - & - \\
\hline SP_2218 & MreC; rod shape-determining protein & - & - & - & - & - & - & - & - & - & - \\
\hline SP_rrnaA23S & $23 \mathrm{~S}$ ribosomal RNA; K01980 $23 \mathrm{~S}$ ribosomal RNA & - & - & - & - & - & - & - & - & - & - \\
\hline SP_rrnaB23S & $23 \mathrm{~S}$ ribosomal RNA; K01980 $23 \mathrm{~S}$ ribosomal RNA & - & - & - & - & - & - & - & - & - & - \\
\hline SP_rrnaC23S & 23 S ribosomal RNA; K0198023S ribosomal RNA & - & - & - & - & - & - & - & - & - & - \\
\hline SP_rrnaD23S & $23 \mathrm{~S}$ ribosomal RNA; K01980 $23 \mathrm{~S}$ ribosomal RNA & - & - & - & - & - & - & - & - & - & - \\
\hline
\end{tabular}

${ }^{a}$ All S. pneumoniae loci number (sp_\#) are according to the annotation of reference strain TIGR4

associated with virulence and antibiotics resistance. Resistant isolates to all four antibiotics have higher numbers of SNPs associated with virulent genes than susceptible isolates (SPS4 and SPS6), suggesting that the presence of certain SNPs could be more related to drugresistance (Fig. 4). Genes encoding capsular polysaccharide (CPS) biosynthesis proteins Cps4E, Cps4F, Cps4G, and $\mathrm{Cps} 4 \mathrm{H}$ did not possess any mutations amongst all the pneumococcal isolates (Table 5).

\section{Phylogenetic analysis of S. pneumoniae isolates}

A parsimony tree with respect to reference and 10 isolates was generated from the kSNP3 pipeline, parsimony tree is consensus tree based on all of the SNPs identified between the reference genome TIGR4 and the 10 isolates. Branch lengths are expressed in terms of changes per number of SNPS. Our result showed that isolates SPS3, SPS4, SPS5, and SPS6 were closest to each other, while isolates SPS8, SPS9, and SPS10 were closely related to each other. All these eight isolates formed one clade. On the other hand isolates SPS1, SPS2, and SPS7 were closely related to each other (Fig. 5).

\section{Discussion}

WGS has become an essential tool to elucidate the mechanisms used by bacteria to resist various antibiotics. In the present study, we have investigated the genomic variations and mutations among genes associated with virulence and antibiotic resistance in 10 clinical isolates of S. pneumoniae selected based on their susceptibility profiles against four antibiotics. Using WGS technique, the full genomic sequences of the 10 isolates were compared to that of the S. pneumoniae reference genome TIGR4.

Whole genome sequencing of the 10 isolates has revealed a high degree of sequence conservation between the pneumococcal isolates regardless of their susceptibility to antibiotics. This high sequence similarity of the isolates could possibly be explained by the low number of isolates and also by the fact that all the isolates had been collected from the same hospital. Nevertheless, 
Table 6 Unique non-synonymous single nucleotide polymorphisms (SNPs) associated with penicillin binding proteins (PBPs) and other virulent genes found in all ten pneumococcal isolates isolates

\begin{tabular}{|c|c|c|c|c|c|c|}
\hline Locus Name & $\begin{array}{l}\text { Putative } \\
\text { Identification }\end{array}$ & $\begin{array}{l}\text { Reference } \\
\text { Position }\end{array}$ & TIGR4 & SNP & $\begin{array}{l}\text { Pneumococcal } \\
\text { isolate }\end{array}$ & $\begin{array}{l}\text { Amino Acid } \\
\text { Change }\end{array}$ \\
\hline \multirow[t]{11}{*}{ SP_0346 } & \multirow{11}{*}{$\begin{array}{l}\text { cpsA; capsular polysaccharide } \\
\text { biosynthesis protein }\end{array}$} & 320,234 & C & $T$ & SPS7, SPS8, SPS10 & A53V \\
\hline & & 320,204 & C & $\mathrm{T}$ & SPS7, SPS8 & A43V \\
\hline & & 320,872 & C & $\mathrm{T}$ & SPS10 & P266S \\
\hline & & 321,451 & G & A & SPS10 & V459 M \\
\hline & & 320,657 & C & $\mathrm{T}$ & SPS9, SPS10 & S194 L \\
\hline & & 321,460 & A & G & SPS2 & $1462 \mathrm{~V}$ \\
\hline & & 321,485 & $\mathrm{~T}$ & C & SPS7, SPS8 & V470A \\
\hline & & 320,710 & A & G & SPS1 & $\mathrm{T} 212 \mathrm{~A}$ \\
\hline & & 322,321 & A & G & SPS10 & K20E \\
\hline & & 322,360 & G & A & SPS2 & G33S \\
\hline & & 323,191 & A & C & SPS1, SPS7, SPS8 & $\mathrm{N} 76 \mathrm{H}$ \\
\hline SP_1837 & $\begin{array}{l}\text { capsular polysaccharide } \\
\text { biosynthesis protein }\end{array}$ & $1,746,914$ & $\mathrm{~T}$ & C & SPS1, SPS9, SPS10 & $\mathrm{K} 212 \mathrm{R}$ \\
\hline \multirow[t]{3}{*}{ SP_0117 } & \multirow{3}{*}{$\begin{array}{l}\text { pspA; pneumococcal } \\
\text { surface protein A }\end{array}$} & 118,490 & C & $\mathrm{T}$ & SPS9 & $\mathrm{T} 23 \mathrm{M}$ \\
\hline & & 120,431 & C & A & SPS7, SPS8 & A670D \\
\hline & & 118,496 & A & C & SPS7, SPS8, SPS10 & Q25P \\
\hline SP_0799 & $\begin{array}{l}\text { ciaH; sensor histidine } \\
\text { kinase ClaH }\end{array}$ & 753,163 & C & G & SPS7, SPS8 & $\mathrm{H} 180 \mathrm{D}$ \\
\hline SP_1923 & pln; pneumolysin & $1,832,851$ & G & A & SPS9 & T154 M \\
\hline \multirow[t]{2}{*}{ SP_0369 } & \multirow{2}{*}{$\begin{array}{l}\text { penicillin-binding } \\
\text { protein } 1 \mathrm{~A}\end{array}$} & 347,479 & C & $\mathrm{T}$ & SPS2 & $\mathrm{E} 512 \mathrm{~K}$ \\
\hline & & 348,706 & $\mathrm{~T}$ & A & SPS2 & $\mathrm{T} 103 \mathrm{~S}$ \\
\hline SP_2099 & $\begin{array}{l}\text { penicillin-binding } \\
\text { protein 1B }\end{array}$ & $2,006,807$ & A & G & SPS10 & V787A \\
\hline \multirow[t]{3}{*}{ SP_2010 } & \multirow{3}{*}{$\begin{array}{l}\text { penicillin-binding } \\
\text { protein } 2 \mathrm{~A}\end{array}$} & $1,917,863$ & $\mathrm{~T}$ & C & SPS9, SPS10 & E17G \\
\hline & & $1,916,459$ & $\mathrm{~T}$ & G & SPS9 & A485E \\
\hline & & $1,916,166$ & C & $\mathrm{T}$ & SPS9 & A583T \\
\hline \multirow[t]{5}{*}{ SP_1673 } & \multirow{5}{*}{$\begin{array}{l}\text { penA; penicillin-binding } \\
\text { protein } 2 \mathrm{~B}\end{array}$} & $1,573,212$ & C & A & SPS9 & L609F \\
\hline & & $1,574,933$ & C & $\mathrm{T}$ & SPS3 & V36l \\
\hline & & $1,573,493$ & C & A & SPS2 & A516S \\
\hline & & $1,574,288$ & C & A & SPS2, SPS3 & A251S \\
\hline & & $1,574,461$ & G & A & SPS2 & A193V \\
\hline \multirow[t]{3}{*}{ SP_0336 } & \multirow[t]{3}{*}{ penicillin-binding protein $2 X$} & 308,341 & G & A & SPS9 & D488N \\
\hline & & 307,393 & G & A & SPS2, SPS3 & $\mathrm{A} 172 \mathrm{~T}$ \\
\hline & & 309,113 & C & A & SPS3 & T745 K \\
\hline
\end{tabular}

these results are in agreement with previous studies showing that closely related isolates may possess different levels of resistance to antibiotics [40]. The genes known to be involved in antibiotic resistance are well conserved among all the 10 isolates; however, we were able to identify many mutations that differentiate resistant form susceptible isolates.

Our results showed that the majority of the SNPs occur in the resistant strains rather than the susceptible strains (Fig. 3). For instance, penicillin-resistant isolates showed a greater number of SNPs (3301) compared to susceptible isolates (281 SNPs). Figure 3 reveals that the highest numbers of SNPs among all the isolates are present in prtA, CpsD, CbpE, CbpA, CbpD, and CpsA. These genes could play a role in pneumococcal resistance to antibiotics. We were able to identify 90 non-synonymous SNPs associated with the essential genes of the resistant isolates, and some of them have reappeared in more than one resistant isolate, while none of them have occurred in susceptible strains (Additional file 3 ). Figure 4 shows that resistant 


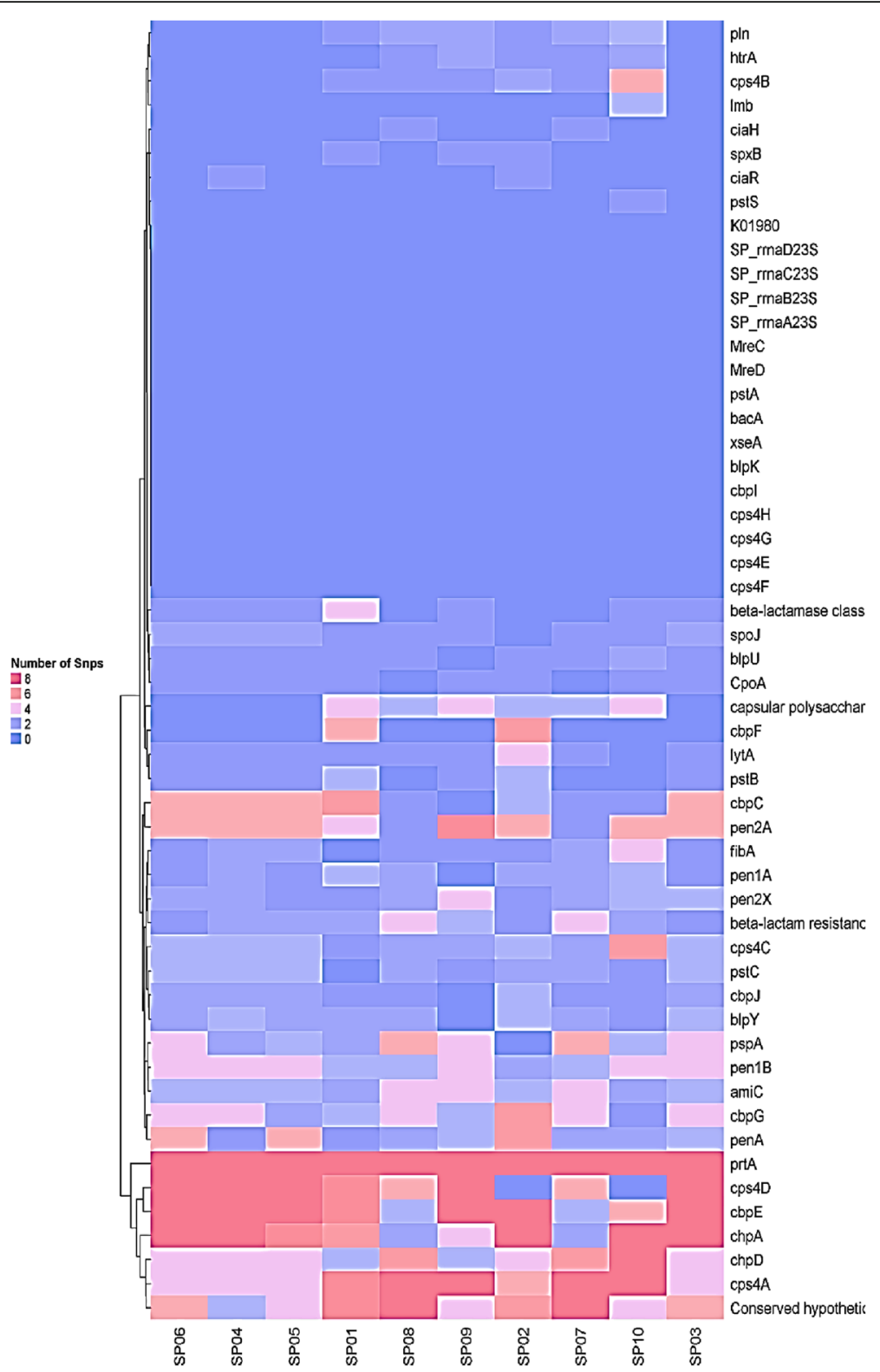

Fig. 3 Heatmap represents the number of Non-synonymous SNPs from S. pneumoniae isolates from antibiotic-resistance genes

isolates possess a higher number of SNPs associated with virulent genes than the susceptible isolates (SPS4 and SPS6). These results suggest that the presence of particular SNPs could play a role in conferring resistance to antibiotics. Out of these 90 SNPs, 31 were unique and found in penicillin binding proteins (PBP1A, PBP1B, PBP2A, PBP2B, and PBP2X), virulent genes (pneumolysin and PspA), sensor histidine kinase (ciaH), and CpsA; capsular polysaccharide biosynthesis protein (Table 6). However, the role of these SNPs in antibiotic resistance need to be investigated as some of them especially those related to penicillin binding proteins were also present in isolates SPS8 and SPS9 that are susceptible to penicillin.
In our study, we observed that genes encoding capsular polysaccharide biosynthesis proteins $\mathrm{CpsE}$, CpsF, $\mathrm{CpsG}$, and $\mathrm{CpsH}$ did not contribute to antibiotic resistance in all the resistant-types (Table 5). On the other hand, our results revealed that several novel mutations are present within capsular biosynthesis genes CpsA, $\mathrm{CpsB}, \mathrm{CpsC}$, and $\mathrm{CpsD}$ associated with resistant isolates (Table 3). The synthesis of capsular polysaccharides is regulated by a set of genes located at the same locus (cps) between $\operatorname{dexB}$ and aliA. Except for serotypes 3 and 37, the first four genes of cps locus (CpsA-D) are common in all pneumococcal serotypes. These four genes encode proteins that affect the level of CPS expression 


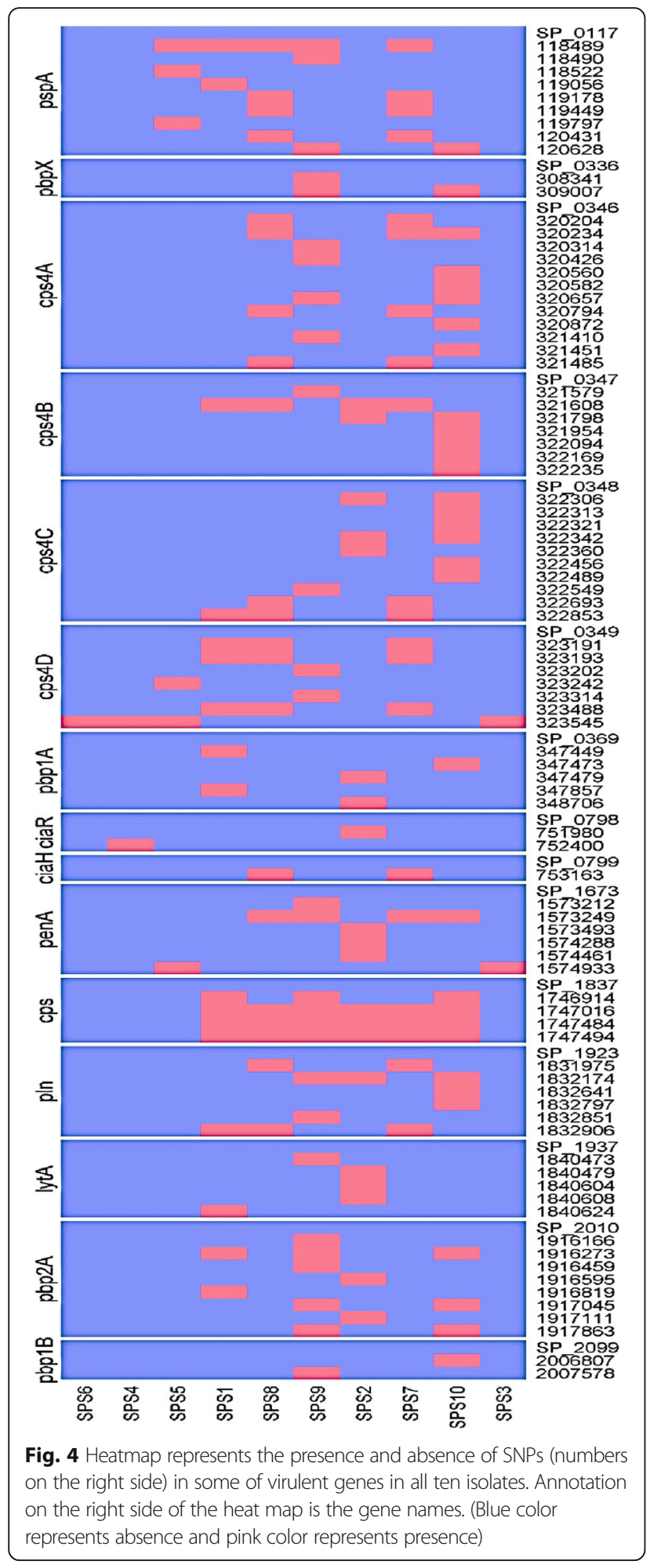

[41]. Although CpsA has no impact on the transcription of CPS in S. pneumoniae, a mutant of pneumococcus lacking CpsA has been shown to produce a reduced level of CPS [42]. CpsB is a manganese-dependent phosphotyrosineprotein phosphatase; it has been shown that $\mathrm{CpsB}$ is necessary for the dephosphorylation of CpsD. Mutants with CpsB deletions tend to have an increased level of phosphorylated CpsD, which leads to a significant decrease in production of CPS [43]. CpsC is a membrane protein required for CpsD tyrosine autophosphorylation. A novel role for $\mathrm{CpsC}$ in the attachment of CPS to the pneumococcal cell wall has been identified recently [44]. CpsD is an auto-phosphorylating tyrosine kinase. Mutations in CpsD affecting the ATPbinding domain eliminate CPS production in S. pneumococcus. Therefore, the capsular genes $\mathrm{CpsB}, \mathrm{CPsC}$ and $\mathrm{CpsD}$ work together to regulate CPS biosynthesis [43, 44].

S. pneumoniae resists penicillin and other $\beta$-lactams by altering PBPs, the main enzymes involved in the final stage of cell wall synthesis. Six PBPs have been identified in pneumococcus PBP1a, 1b, 2×, 2a, 2b, and 3 [15]. Mutations in three of the PBPs (PBP2b, PBP2x, and PBP1a) have the most significant effect on $\beta$-lactams resistance. Several groups have reported mutations in genes encoding PBPs [45-47]. The MIC levels for isolates SPS1 and SPS2 were $2 \mu \mathrm{g} / \mathrm{ml}$ for penicillin and $1 \mu \mathrm{g} / \mathrm{ml}$ for cefotaxime. On the other hand, SPS7 and SPS10 showed the same level of resistance toward penicillin but an increased resistance for cefotaxime $(2 \mu \mathrm{g} / \mathrm{ml})$. Through our analysis, we were able to identify a non-synonymous SNP (G597E) in both SPS7 and SPS10 associated with penicillin binding protein PBP2B. The same SNP was found in isolates SPS8 and SPS9, and both of these two isolates showed high MICs toward cefotaxime ( $>8 \mu \mathrm{g} / \mathrm{ml}$ and $8 \mu \mathrm{g} / \mathrm{ml}$, respectively) (Additional file 3). However, our results showed that all the pneumococcal isolates regardless of their sensitivity to penicillin possess same mutations in the genes encoding penicillin-binding proteins, confirming previous reports that showed that these proteins are not the only determinants of penicillin resistance [48]. Furthermore, we were able to identify a unique mutation (H180D) in the sensor histidine kinase gene ( $\mathrm{ciaH})$ in resistant isolates only (Additional file 3 ). Mutations in ciaH increase resistance to $\beta$-lactams, as this gene is involved in the biosynthesis of cell wall components [49].

The phylogenetic relationships among different clinical isolates of S. pneumonaie were examined using the parsimony tree based on SNPs from whole genome sequencing. From the results, we observed that isolates SPS1 and SPS2 were clustered in one clade; isolates SPS8, SPS9, and SPS10 grouped in one clade; and isolates SPS4, SPS5 and SPS6 clustered in different clade (Fig. 5). These results are consistent with the MIC profile of the 10 isolates (Table 2). The observations that pneumococcal isolates with similar MIC profile were grouped together in a phylogenetic 


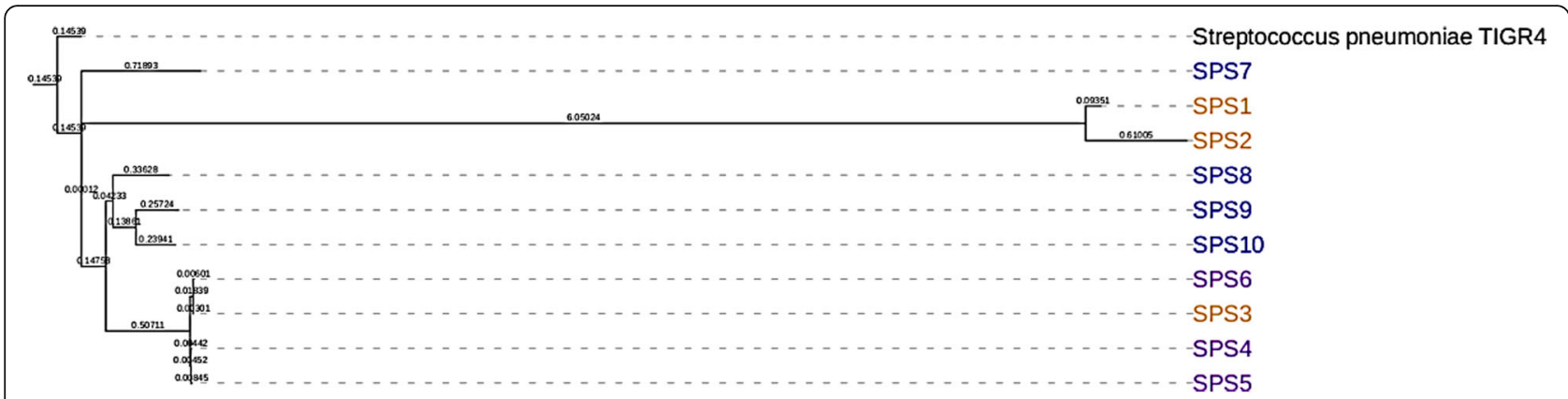

Fig. 5 Parsimony tree with respect to reference and ten isolates was generated from kSNP3 pipeline. Parsimony tree is consensus tree based all of the SNPs identified between the reference and isolates. Branch lengths are expressed in terms of changes per number of SNP

tree suggest that they possess common mutations and were probably originated from the common clone. It is possible that these strains could have evolved and acquired mutations in a similar manner due to selection pressures. Surprisingly, our results revealed that resistant isolate SPS3 was closely related to the susceptible isolates SPS4, SPS5, and SPS6. Among all the resistant isolates, SPS10 showed the highest number of SNPs (34 SNPs) (Table 3). On the other hand, SPS3 was the least resistant isolate having nonsynonymous SNPs compared to other resistant isolates. Moreover, three non-synonymous SNPs (I178T, V22A, and T19A) were common among all the resistant isolates except isolate SPS3 (Additional file 3). This finding suggests that SPS3 could resist antibiotics using a unique mechanism as compared to other resistant isolates. The high phylogenetic relatedness among the clinical pneumococcal isolates with similar MIC profile is related to the specific SNPs in the mutated genes. The presence of identical uncommon mutations, as well as certain genes in the grouped isolates in the phylogenetic tree, is indicative of a single cluster of strains circulating in the population. For instance, the mutations S29A in cpsB, H197L in cpsC, M79I in cpsD, and Q136K in Ply were all found in isolates SPS1, SPS7, and SPS8 (Table 4). All three isolates are closely related to each other in the phylogenetic tree (Fig. 5). Similarly, certain genes such as SP_0461, SP_0463, SP_0357, and SP_1765 were only found in pneumococcal isolates SPS3, SPS4, SPS5, and SPS6 (Additional file 1).

\section{Conclusion}

In conclusion, this study compared the genomic sequences of 10 pneumococcal isolates with different susceptibility to multiple antibiotics. The high degree of sequence conservation and the presence of the same SNPs especially those related to genes involved in $\beta$-lactam resistance in both sensitive and resistant isolates, makes it a difficult task to identify distinct mechanisms of resistance that differentiate strains with different drug-sensitivities, and that antibiotic resistance cannot be only linked to the presence of certain genes. These results are in agreement with previous assumptions that bacterial virulence is the result of a gathering of pathogenicity-related genes that interact in various combinations [50] and that multi-drug resistance could be a result of combinations of mutations that lead to overexpression of several multi-drug efflux pumps; outer membrane porins, $\beta$-lactam acylases and enzymes and structural components involved in peptidoglycan stability (targets of $\beta$ lactams); gyrase mutations; and aminoglycoside phosphotransferases and-acetylases [40]. We were able to identify unique SNPs associated with virulent genes that could have a possible role in resistance to various antibiotics. To confirm these results future studies on virulence gene knockouts are needed to link the role of antibiotic resistance with these genes. This study was also limited by the relatively small number of isolates included in the analysis. Moreover, all resistant genes have yet to be subjected to individual mutational analysis. This can be achieved by introducing the SNPs on the resistant genes by site-directed mutagenesis and further expression analysis. The development of bacterial resistance towards antibiotics is a complex mechanism and multiple genetic alterations such as addition/deletion of specific genes, mutations, or a combination of both could be involved in the process. Whole genome sequencing can be utilised in conjunction with current epidemiological studies, diagnostic assays, and antimicrobial susceptibility tests to understand the genetic variation and pathogen biology of "high-risk" bacteria. It is also important to note that $t$.

\section{Additional files}

Additional file 1: Assembly and gene content of all the ten pneumococcal clinical isolates. (XLSX $288 \mathrm{~kb}$ )

Additional file 2: Full list of non-synonymous single nucleotide polymorphisms (SNPS) in all ten pneumococcal clinical isolates. (XLSX $8827 \mathrm{~kb})$ 
Additional file 3: Conserved non-synonymous single nucleotide polymorphisms (SNPs) associated with penicillin binding proteins (PBPs) and other virulent genes found in resistant isolates. (DOCX 29 kb)

\section{Acknowledgements}

Not applicable.

\section{Funding}

This study was supported by University of Malaya High Impact Research Grant (reference number: UM.C/HIR/MOHE/MED/40, account number: $\mathrm{H}-848$ 20001-E000079) and University of Malaya Research Grant (UMRG Project no. RP020C-14AFR and RP001C-13ICT).

\section{Availability of data and materials}

The draft genome assemblies for the ten isolates have been submitted to NCBI bioproject under the project accession number PRJNA317517 (http:// www.ncbi.nlm.nih.gov/bioproject/317517).

\section{Transparency declarations}

None to declare.

\section{Authors' contributions}

SDS designed the experiments, selected the isolates, funded the project and helped write and approve the manuscript, LCF assisted in the design and testing of laboratory tests on the isolates, HMJ performed the experiments, assisted in analysis and drafting of the manuscript, BR assisted in analysis and sequence allignment, RM helped fund the salaries of research assistants, designing and in manuscript drafting and RR performed the statistical analysis. All authors read and approved the final manuscript.

\section{Ethics approval and consent to participate}

Not applicable.

\section{Consent for publication}

Not applicable.

\section{Competing interests}

The authors declare that they have no competing interests.

\section{Publisher's Note}

Springer Nature remains neutral with regard to jurisdictional claims in published maps and institutional affiliations.

\section{Author details}

${ }^{1}$ Department of Medical Microbiology, University of Malaya, 50603 Kuala Lumpur, Malaysia. ${ }^{2}$ Department of Biological Sciences, School of Science and Technology, Sunway University, 47500 Kuala Lumpur, Malaysia. ${ }^{3}$ School of Pharmacy, University of Nottingham Malaysia Campus, 43500 Semenyih, Selangor, Malaysia. ${ }^{4}$ Sengenics HIR, University Malaya, 50603 Kuala Lumpur, Malaysia. ${ }^{5}$ Department of Trauma and Emergency, University Malaya Medical Centre, 50603 Kuala Lumpur, Malaysia. ${ }^{6}$ Department of Microbiology, Faculty of Medicine, MAHSA University, 42610 Jenjarom, Malaysia.

Received: 21 August 2017 Accepted: 29 January 2018

Published online: 15 February 2018

\section{References}

1. van der Poll T, Opal SM. Pathogenesis, treatment, and prevention of pneumococcal pneumonia. Lancet. Elsevier Ltd. 2009;374:1543-56. Available from: https://doi.org/10.1016/S0140-6736(09)61114-4

2. Alonso DE, Verheul AF, Verhoef J, Snippe H. Streptococcus Pneumoniae: virulence factors, pathogenesis, and vaccines. Microbiol Rev. 1995;59:591603. Available from: www.ncbi.n/m.nih.gov/clinvar/variation/239389/.

3. Henriques-Normark B, Tuomanen El. The pneumococcus: Epidemiology, microbiology, and pathogenesis. Cold Spring Harb Perspect Med. 2013;3: a010215.

4. Organization WH. Report of a meeting on priorities for pneumococcal and Haemophilus influenzae type $b$ ( Hib ) vaccine development and introduction. Who. 2001;9-12. Available from: https://www.ncbi.nlm.nih. gov/pmc/articles/PMC2907394/.
5. O'Brien KL, Wolfson LJ, Watt JP, Henkle E, Deloria-Knoll M, McCall N, et al. Burden of disease caused by Streptococcus Pneumoniae in children younger than 5 years: global estimates. Lancet. Elsevier Ltd. 2009;374:893902. Available from: https://doi.org/10.1016/S0140-6736(09)61204-6

6. Bogaert D, De Groot R, Hermans PWM. Streptococcus Pneumoniae colonisation: the key to pneumococcal disease. Lancet Infect Dis. 2004;4:144-54.

7. Obaro S, Adegbola R. The pneumococcus: carriage, disease and conjugate vaccines. J Med Microbiol. 2002;51:98-104.

8. Bravo LC. Overview of the disease burden of invasive pneumococcal disease in Asia. Vaccine. 2009;27:7282-91.

9. Lin T-Y, Shah NK, Brooks D, Garcia CS. Summary of invasive pneumococcal disease burden among children in the Asia-Pacific region. Vaccine. Elsevier Ltd. 2010;28:7589-605. Available from: https://www.ncbi.nlm.nih.gov/ pubmed/20674872.

10. Jones RN, Jacobs MR, Sader HS. Evolving trends in Streptococcus Pneumoniae resistance: implications for therapy of community-acquired bacterial pneumonia. Int J Antimicrob Agents. 2010;36:197-204.

11. Muhammad RD, Oza-Frank R, Zell E, Link-Gelles R, Narayan KMV, Schaffner W, et al. Epidemiology of invasive pneumococcal disease among high-risk adults since the introduction of pneumococcal conjugate vaccine for children. Clin Infect Dis. 2013;56:59-67.

12. Kadioglu A, Weiser JN, Paton JC, Andrew PW. The role of Streptococcus Pneumoniae virulence factors in host respiratory colonization and disease. Nat Rev Microbiol. 2008;6:288-301. Available from: http://www.ncbi.nlm.nih. gov/pubmed/18340341

13. McCool TL. The immune response to pneumococcal proteins during experimental human carriage. J Exp Med. 2002;195:359-65.

14. Jacobs MR. Streptococcus Pneumoniae: epidemiology and patterns of resistance. Am J Med Suppl. 2004;117:3-15.

15. Zapun A, Contreras-Martel C, Vernet T. Penicillin-binding proteins and $\beta$ lactam resistance. FEMS Microbiol Rev. 2008;32:361-85.

16. Grebe T, Hakenbeck R. Penicillin-binding proteins $2 b$ and $2 x$ of Streptococcus Pneumoniae are primary resistance determinants for different classes of beta-lactam antibiotics. Antimicrob Agents Chemother. 1996:40:829-34.

17. Poole K. Resistance to beta-lactam antibiotics. Cell Mol Life Sci. 2004;61: 2200-23.

18. Cornick JE, Bentley SD. Streptococcus Pneumoniae: the evolution of antimicrobial resistance to beta-lactams, fluoroquinolones and macrolides. Microbes Infect. Elsevier Masson SAS. 2012;14:573-83.

19. Charpentier $E$, Tuomanen E. Mechanisms of antibiotic resistance and tolerance in Streptococcus Pneumoniae. Microbes Infect. 2000;2:1855-64.

20. Jones RN, Sader HS, Mendes RE, Flamm RK. Update on antimicrobial susceptibility trends among Streptococcus Pneumoniae in the United States: report of ceftaroline activity from the SENTRY antimicrobial surveillance program (1998-2011). Diagn Microbiol Infect Dis. Elsevier Inc. 2013;75:107-9.

21. Ventola CL. The antibiotic resistance crisis: part 1: causes and threats. P T a peer-reviewed J. Formul Manag. 2015;40:277-83.

22. Hackel M, Lascols C, Bouchillon S, Hilton B, Morgenstern D, Purdy J. Serotype prevalence and antibiotic resistance in Streptococcus Pneumoniae clinical isolates among global populations. Vaccine. Elsevier Ltd. 2013;31: 4881-7. Available from: https://doi.org/10.1016/j.vaccine.2013.07.054

23. Cui L, Neoh H, Shoji M, Hiramatsu K. Contribution of vraSR and graSR point mutations to vancomycin resistance in vancomycin-intermediate Staphylococcus Aureus. Antimicrob Agents Chemother. 2009;53:1231-4.

24. Köser CU, Ellington MJ, Peacock SJ. Whole-genome sequencing to control antimicrobial resistance. Trends Genet. 2014;30:401-7.

25. Palmer AC, Kishony R. Understanding, predicting and manipulating the genotypic evolution of antibiotic resistance. Nat Rev Genet. 2013;14:243-8.

26. Feng J, Lupien A, Gingras H, Wasserscheid J, Dewar K, Légaré D, et al. Genome sequencing of linezolid-resistant Streptococcus Pneumoniae mutants reveals novel mechanisms of resistance. Genome Res. 2009;19:1214-23.

27. Pai R, Gertz RE, Beall B. Sequential multiplex PCR approach for determining capsular serotypes of Streptococcus Pneumoniae isolates. J Clin Microbiol. 2006:44:124-31.

28. Schmieder R, Edwards R. Quality control and preprocessing of metagenomic datasets. Bioinformatics. 2011;27(6):863-64.

29. Bankevich A, Nurk S, Antipov D, A a G, Dvorkin M, Kulikov AS, et al. SPAdes: a new genome assembly algorithm and its applications to single-cell sequencing. J Comput Biol. 2012;19:455-77. 
30. Mikheenko A, Saveliev V, Gurevich A. MetaQUAST: evaluation of metagenome assemblies. Bioinformatics. Oxford University Press. 2016;32:1088-90.

31. Li H, Coghlan A, Ruan J, Coin LJ, Hériché J-K, Osmotherly L, et al. TreeFam: a curated database of phylogenetic trees of animal gene families. Nucleic Acids Res. 2006;34:D572-80.

32. Gardner SN, Slezak T, Hall BG. KSNP3.0: SNP detection and phylogenetic analysis of genomes without genome alignment or reference genome. Bioinformatics. 2015;31:2877-8.

33. Tettelin H, Nelson KE, Paulsen IT, J a E, Read TD, Peterson S, et al. Complete genome sequence of a virulent isolate of Streptococcus Pneumoniae. Science. 2001;293:498-506.

34. Langmead B, Salzberg S. Fast gapped-read alignment with bowtie 2. Nat Methods. 2012;9:357-9.

35. Chen L, Xiong Z, Sun L, Yang J, Jin Q. VFDB 2012 update: toward the genetic diversity and molecular evolution of bacterial virulence factors. Nucleic Acids Res. 2012;40:D641-5.

36. Song X-M, Connor W, Jalal S, Hokamp K, A a P. Microarray analysis of Streptococcus Pneumoniae gene expression changes to human lung epithelial cells. Can J Microbiol. 2008;54:189-200.

37. Chen L, Yang J, Yu J, Yao Z, Sun L, Shen Y, et al. VFDB: a reference database for bacterial virulence factors. Nucleic Acids Res. 2005;33:325-8.

38. Orihuela CJ, Radin JN, Sublett JE, Gao G, Kaushal D, Tuomanen El. Microarray analysis of pneumococcal gene expression during invasive disease. Infect Immun. 2004;72:5582-96.

39. Rogers PD, Liu TT, Barker KS, Hilliard GM, English BK, Thornton J, et al. Gene expression profiling of the response of Streptococcus Pneumoniae to penicillin. J Antimicrob Chemother. 2007;59:616-26.

40. Jansen G, Mahrt N, Tueffers L, Barbosa C, Harjes M, Adolph G, et al. Association between clinical antibiotic resistance and susceptibility of Pseudomonas in the cystic fibrosis lung. Evol Med Public Heal. 2016; eow016. Available from: http://www.ncbi.nlm.nih.gov/pubmed/27193199

41. Morona JK, Paton JC, Miller DC, Morona R. Tyrosine phosphorylation of CpsD negatively regulates capsular polysaccharide biosynthesis in streptococcus pneumoniae. Mol Microbiol. 2000;35:1431-42.

42. Bender MH, Cartee RT, Yother J. Positive correlation between tyrosine phosphorylation of CpsD and capsular polysaccharide production in Streptococcus Pneumoniae. J Bacteriol. 2003:185:6057-66.

43. Morona J, Morona R, Miller D. Mutational analysis of the carboxy-terminal (YGX) 4 repeat domain of CpsD, an autophosphorylating tyrosine kinase required for capsule biosynthesis in. J Bacteriol. 2003;185:3009-19.

44. Morona JK, Morona R, Paton JC. Attachment of capsular polysaccharide to the cell wall of Streptococcus Pneumoniae type 2 is required for invasive disease. Proc Natl Acad Sci U S A. 2006;103:8505-10.

45. Chewapreecha C, Marttinen P, Croucher NJ, Salter SJ, Harris SR, Mather AE, et al. Comprehensive identification of single nucleotide polymorphisms associated with Beta-lactam resistance within pneumococcal mosaic genes. PLoS Genet. 2014;10:e1004547.

46. Fani $F$, Leprohon $P$, Légaré $D$, Ouellette $M$. Whole genome sequencing of penicillin-resistant Streptococcus Pneumoniae reveals mutations in penicillin-binding proteins and in a putative iron permease. Genome Biol BioMed Central Ltd. 2011;12:R115.

47. Fani F, Brotherton M-C, Leprohon P, Ouellette M. Genomic analysis and reconstruction of cefotaxime resistance in Streptococcus Pneumoniae. J Antimicrob Chemother. 2013;68:1718-27.

48. Grebe T, Paik J, Hakenbeck R. A novel resistance mechanism against??lactams in Streptococcus Pneumoniae involves CpoA, a putative glycosyltransferase. J Bacteriol. 1997;179:3342-9.

49. Hakenbeck R, Grebe T, Zähner D, Stock JB. Beta-lactam resistance in Streptococcus Pneumoniae: penicillin-binding proteins and non-penicillinbinding proteins. Mol. Microbiol. 1999;33:673-8.

50. Sánchez D, Gomila M, Bennasar A, Lalucat J, García-Valdes E. Genome analysis of environmental and clinical P. Aeruginosa isolates from sequence type-1146. PLoS One 2014;9.

51. Alikhan N-F, Petty NK, Ben Zakour NL, Beatson S a. BLAST ring image generator (BRIG): simple prokaryote genome comparisons. BMC Genomics BioMed Central Ltd. 2011;12:402.

\section{Submit your next manuscript to BioMed Central and we will help you at every step:}

- We accept pre-submission inquiries

- Our selector tool helps you to find the most relevant journal

- We provide round the clock customer support

- Convenient online submission

- Thorough peer review

- Inclusion in PubMed and all major indexing services

- Maximum visibility for your research

Submit your manuscript at www.biomedcentral.com/submit

) Biomed Central 